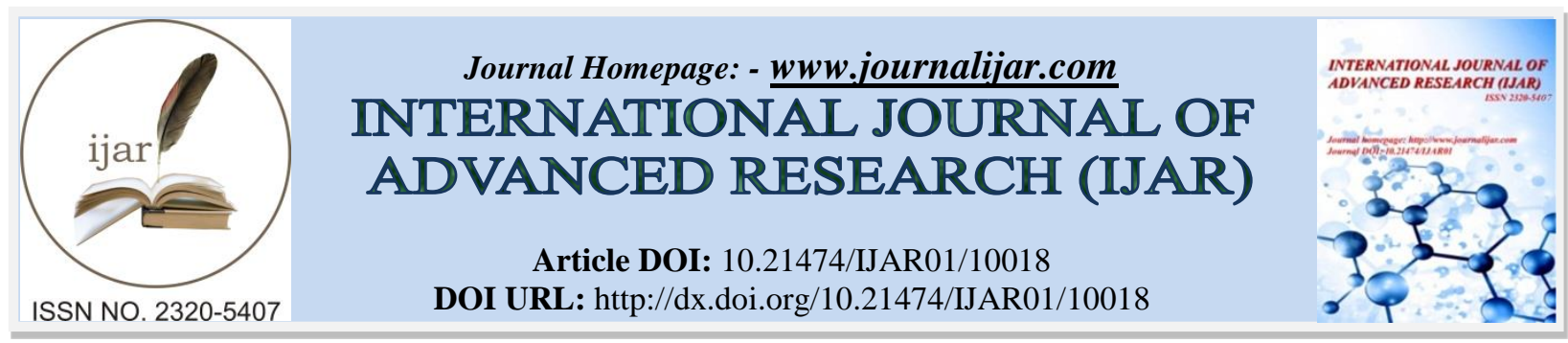

RESEARCH ARTICLE

\title{
PSYCHOLOGICAL OUTCOME OF PATIENTS UNDERGOING CORONARY ARTERY BYPASS GRAFT (CABG) AND VALVULAR SURGERIES IN JIPMER, PUDUCHERRY.
}

\author{
Aruna $P^{1}$, Dr. Lakshmi Ramamoorthy ${ }^{2}$ and Dr. Durga Prasad Rath ${ }^{3}$. \\ 1. M.Sc nursing, Tutor, JIPMER, Puducherry, India. \\ 2. Assistant Professor, Phd, JIPMER, Puducherry, India. \\ 3. Associate Professor, JIPMER, Puducherry, India.
}

\section{Manuscript Info}

\section{Manuscript History}

Received: 08 September 2019

Final Accepted: 10 October 2019

Published: November 2019

Key words:-

Outcome, Quality of life, anxiety, CABG.

\begin{abstract}
Introduction: Coronary artery disease and valvular heart disease are common among cardiovascular diseases and the burden of CAD and valvular heart disease is enormous, for the patients as well as for the country. Both CABG \& valvular surgery are performed to improve functional capability and quality of life.

Aim: To assess the psychological outcome of patients undergoing Coronary artery bypass graft and valvular surgeries.

Methods: In this prospective observational study, 40 patients who underwent coronary artery bypass graft or valvular surgery were selected through consecutive sampling method from August 2018 to February 2018. The tools used for data collection were short form 36 questionnaire and Zung anxiety scale to assess the quality of life and anxiety level respectively.

Results: In both CABG \& valve groups, postoperative quality of life improved in all dimensions comparing to preoperative quality of life including physical functioning $(\mathrm{p}<0.002, \mathrm{p}<0.000)$, role limitations due to physical health $(\mathrm{p}<0.013, \mathrm{p}<0.000)$, role limitations due to emotional problems $(\mathrm{p}<0.005, \mathrm{p}<0.000)$, energy/fatigue $(\mathrm{p}<0.00, \mathrm{p}<$ $0.000)$, emotional wellbeing $(\mathrm{p}<0.001, \mathrm{p}<0.000)$, social functioning $(\mathrm{p}<1, \mathrm{p}<0.108)$, pain $(\mathrm{p}<0.006, \mathrm{p}<0.001)$, perception of general health $(\mathrm{p}<0.000, \mathrm{p}<0.000)$.

Conclusion: Coronary artery bypass graft and valve surgeries improve the quality of life in patients with coronary artery disease and valvular heart disease.
\end{abstract}

Copy Right, IJAR, 2019,. All rights reserved.

\section{Introduction:-}

Cardiovascular diseases (CVDs) have become the most important cause of non - communicable disease deaths. According to WHO statistics, cardiovascular diseases are the most common cause of deaths in the world. In 2015, 17.7 million deaths were due to CVDs, representing $31 \%$ of all deaths in the world. Of these deaths, approximately 7.4 million deaths were from ischemic heart disease. According to Global Burden of Disease Report, the agestandardized mortality rate in India is 272 per 100000 population which is higher than the global average rate of 235 per 100000 .

Corresponding Author:-Aruna P.

Address:-M.Sc nursing, Tutor, JIPMER, Puducherry, India. 
Next, to ischaemic heart disease (IHD), valvular heart diseases emerged as a common heart disease in clinical practices, and cause increased morbidity and mortality. Around $2 \%$ of deaths attributable to cardiovascular diseases is due to rheumatic heart disease.

\section{Background}

Coronary artery disease and valvular heart disease are common among cardiovascular diseases and the burden of $\mathrm{CAD}$ and valvular heart disease is enormous, for the patients as well as for the country. Both CABG \& valvular surgery are performed to improve functional capability and quality of life. A limited amount of information is available regarding the various factors that are associated with achieving these goals.

Since the huge number of people undergo CABG \& valvular surgeries globally and healthcare expenditures related to these interventions is high, both clients and healthcare providers need to have realistic anticipations about the course of recovery and to identify deviancies from the normal recovery pattern.

Since RHD affects predominantly the younger population in their productive years, it has an enormous socioeconomic impact on the society. So the better postoperative outcome helps them to lead a productive life. This study will help in identifying predictors of outcome after cardiac surgeries. By managing the factors affecting the outcome of CABG and valvular surgeries, the morbidity and mortality can be reduced. This study can help the nurses to provide a comprehensive care to the patients undergoing $\mathrm{CABG}$ and valvular surgeries.

The conceptual framework adopted for the present study was Betty Neuman's System Model. This model emphasizes the individual's relationship to stressors, the reaction to it and levels of intervention.

\section{The Study}

\section{Aim/s}

To assess the psychological outcome and its determinants of patients undergoing Coronary Artery Bypass Graft $(\mathrm{CABG})$ and valvular surgeries and to associate the psychological outcome with socio-demographic and clinical variables of the patients undergoing $\mathrm{CABG} \&$ valvular surgeries.

\section{Research question}

Do the patients undergoing CABG \& Valvular surgeries have better psychological outcome?

\section{Design}

Prospective observational design

\section{Participants}

The consecutive sample of patients who underwent coronary artery bypass and valvular surgery was recruited. The inclusion criteria were Patients with cardiac problems who underwent CABG and valvular surgeries in JIPMER hospital, Puducherry and patients with an adequate level of comprehension, attention, and intelligence, aged more than 18 years. The exclusion criteria were patients who were critically ill in preoperative stage and having significant visual or hearing impairments, patients with the known history of psychiatric disorders.

The sample size is estimated to be $25 \mathrm{CABG}$ and 25 valvular patients based on previous studies $43 \%$ of patients had significant anxiety (psychological outcome) with $20 \%$ relative precision and $5 \%$ level of significant.

\section{Data collection}

Data were collected using Zung anxiety scale, SF-36 quality of life scale. Feasibility of the study was assessed by conducting a pilot study. Approximately $10 \%$ of the sample size (5 patients) were included in the study. Data collected between August 2017 to February 2018.

\section{Ethical}

Approval for carrying out this study was obtained from Nursing research monitoring committee and Institute Ethics Committee, Human studies.

\section{Data analysis}

Demographic variables and clinical variables were analyzed with frequency \& percentage, mean with standard deviation, 
median with interquartile range. Wilcoxan test was used to compare preoperative and postoperative quality of life.

\section{Results:-}

Demographic variables of patients underwent CABG \& valvular surgeries

Majority of the subjects belonged to the age group of 45-59 years (47.1\%) in CABG group. the majority of the subjects belonged to the age group of $45-59$ years $(47.8 \%)$ in valve group. The majority of the study subjects were Males, 15 (88.2\%) in CABG group. the number of Male and Female participants in valve group were 10 (43\%) and $13(57 \%)$, respectively.

Majority of subjects, $13(76.5 \%)$ in CABG group and $8(34.8 \%)$ in valve group had secondary education. A sum of 27 of them in both the groups were skilled workers and 11 of them were unemployed. Totally 38 of them in both groups were married.

\section{Preoperative clinical parameters of patients underwent CABG \& valvular surgeries}

$17.6 \%$ (3) of subjects had diabetes mellitus, $2(11.8 \%)$ had hypertension and $9(53 \%)$ had both diabetes mellitus and hypertension in CABG group. Only one had (4.3\%) diabetes mellitus in valve group. Among 15 subjects who had comorbidities in both groups, 13 were taking treatment regularly. Majority of subjects in CABG group were found to be in NYHA II, 7 (41.2\%) \& NYHA III, 7 (41.2\%) and $14(60.8 \%)$ were found to be in NYHA III among patients underwent valve surgery.

The majority of the participants' preoperative ejection fraction was more than $45 \%$. Out of 23 participants in valve group, $11(47.8 \%)$ found to have preoperative atrial fibrillation. Nearly half of the participants in valve group had a history of previous cardiac operation. The number of participants with high BMI was more in CABG group.

Five $(29.4 \%)$ in CABG group and $4(17.4 \%)$ in valve group were smokers and $9(52.9 \%)$ in CABG group and 2 $(8.7 \%)$ in valve group were alcoholics. A total of 37 participants were non-vegetarians.

Among 17 patients with coronary artery disease, one had left atrial myxoma and one had valvular heart disease. Duration of present illness was less than one year in the majority of subjects and on regular treatment. Increased frequency of triple vessel disease was observed.

Only $23.5 \%$ of participants had a family history of CAD among patients underwent CABG. The frequency of the previous history of MI and USA, CSA were 13(76.4\%), 2(11.8\%) and 2(11.8\%) respectively. On pump CABG was performed commonly, $15(88.2 \%)$ and $2(11.8 \%)$ had off-pump CABG. 1 (5.9\%) had left atrial myxoma excision along with $\mathrm{CABG}$. And one participant had both $\mathrm{CABG}$ and valve replacement.

Common cause of valvular heart disease was RHD. The commonly affected valve was the mitral valve. Increased frequency of surgery on the single valve, $13(56.52 \%)$ was noted, followed by the double valve, $9(39.13 \%)$ and triple valve, $1(4.3 \%)$. A total of $12(52.2 \%)$ participants underwent MVR, $6(26 \%)$ of participants had AVR and 5 (21.7\%) participants had double valve replacement (DVR).

\section{Preoperative and postoperative anxiety level}

Majority of participants had normal range of anxiety preoperatively and postoperatively.

\section{Quality of life}

Quality of life improved postoperatively in all domains with statistical significance in physical functioning, role limitation due to physical health and emotional problems, energy level, emotional well-being, pain, the perception of general health.

Table 10:-Preoperative and Postoperative quality of life in CABG group (Short Form 36 questionnaire)

\begin{tabular}{|l|l|l|l|}
\hline \multirow{3}{*}{ Name of the variables } & \multicolumn{1}{|c|}{$\begin{array}{c}\text { Preoperative } \\
\text { QoL }\end{array}$} & $\begin{array}{c}\text { Postoperative } \\
\text { QoL }\end{array}$ & \multirow{2}{*}{ p-value\# } \\
\cline { 2 - 3 } & Median (IQR) & Median (IQR) & \\
\hline Physical functioning & & & \\
\hline
\end{tabular}




\begin{tabular}{|l|c|c|c|}
\hline $\begin{array}{l}\text { Role limitations due to } \\
\text { physical health }\end{array}$ & $40(27.50-70)$ & $80(72.50-80)$ & $0.002^{*}$ \\
\hline $\begin{array}{l}\text { Role limitations due to } \\
\text { emotional problems }\end{array}$ & $33(0-50)$ & $50(25-62.50)$ & $0.013^{*}$ \\
\hline Energy/ Fatigue & $65(25-80)$ & $90(80-90)$ & $0.005^{*}$ \\
\hline Emotional wellbeing & $64(46-80)$ & $100(80-100)$ & $0.001^{*}$ \\
\hline Social functioning & $100(87.50-100)$ & $90(77.50-100)$ & $0.001^{*}$ \\
\hline Pain & $55(16.50-75)$ & $88(70-90)$ & $0.006^{*}$ \\
\hline $\begin{array}{l}\text { Perception of General } \\
\text { health }\end{array}$ & $58(42-67)$ & $92(80-95.50)$ & $0.000^{*}$ \\
\hline
\end{tabular}

$\mathrm{p}<0.05$ Significant $* * \mathrm{p}<0.01 \quad * * * \mathrm{p}<0.001$ Highly Significant $\quad$ \#Wilcoxon test

Table 11:-Preoperative and Postoperative quality of life in valve group (Short Form 36 questionnaire)

\begin{tabular}{|l|c|c|c|}
\hline \multicolumn{1}{|c|}{ Name of the variables } & $\begin{array}{c}\text { Preoperative } \\
\text { QoL }\end{array}$ & $\begin{array}{c}\text { Postoperative } \\
\text { QoL }\end{array}$ & \multirow{2}{*}{ p-value\# } \\
\cline { 2 - 3 } & Median (IQR) & Median (IQR) & \\
\hline Physical functioning & $25(5-60)$ & $75(70-80)$ & $0.000^{*}$ \\
\hline $\begin{array}{l}\text { Role limitations due to } \\
\text { physical health }\end{array}$ & $0(0-50)$ & $50(50-75)$ & $0.000^{*}$ \\
\hline $\begin{array}{l}\text { Role limitations due to } \\
\text { emotional problems }\end{array}$ & $33(0-100)$ & $100(67-100)$ & $0.000^{*}$ \\
\hline Energy/ Fatigue & $15(5-60)$ & $75(70-80)$ & $0.000^{*}$ \\
\hline Emotional wellbeing & $48(24-72)$ & $88(72-100)$ & $0.000^{*}$ \\
\hline Social functioning & $100(50-100)$ & $88(75-100)$ & 0.108 \\
\hline Pain & $33(0-100)$ & $90(80-90)$ & $0.001^{*}$ \\
\hline Perception of General health & $50(25-67)$ & $90(90-92)$ & $0.000^{*}$ \\
\hline
\end{tabular}

$* \mathrm{p}<0.05$ Significant $\quad * * \mathrm{p}<0.01 * * * \mathrm{p}<0.001$ Highly Significant \#Wilcoxon test

\section{Discussion:-}

Description of the demographic variables

The present study shows that the majority of the subjects belonged to the age group of $45-59$ years (47.1\%) in CABG group and $30-59$ years $(87 \%)$ in valve group. The majority of the study subjects were Males, $15(88.2 \%)$ in CABG group. The majority of subjects, $13(76.5 \%)$ in CABG group had secondary education and $14(82.3 \%)$ were skilled workers and all were married.

A study conducted by Douki et al showed similar results with an average age of participants was (58.27 \pm 9.97$)$. Majority of the participants were male (55.6\%), married (99.5\%), the majority of the patients had less than 5 years of schooling (70.1\%), $78(41.7 \%)$ of them were house worker, duration of cardiac illness in most of the participants $(68.4 \%)$ was (1-5) years.

Among valve group in the present study, $10(43.4 \%)$ were male and $13(56.5 \%)$ female. 7 (30.4\%) had primary education, $8(34.8 \%)$ had secondary education, $2(8.7 \%)$ had graduation, $6(26.1 \%)$ with no formal education, 13 $(56.5 \%)$ skilled workers, 10 (43.5\%) unemployed, $91.3 \%$ of subjects were married. 
A study conducted by Namazi et al showed that the majority of subjects was women (60.8\%) and men (39.2\%) with the average age of $49-59$ years, $89.2 \%$ were married, $43.1 \%$ had primary education and $4.9 \%$ were graduate. Among all participants, $52 \%$ was housewives and $56.9 \%$ had no income, while the minimum number of participants $(6.9 \%)$ had sufficient income.

\section{Clinical parameters}

In CABG group, $17.6 \%$ (3) of subjects had diabetes mellitus, $11.8 \%$ (2) had hypertension and 53\% (9) had both diabetes mellitus and hypertension. In valve group, 1 (4.3\%) had diabetes mellitus. A study conducted by Douki et al shows most of the patients, $47.05 \%$ had hypertension, $37.43 \%$ diabetes mellitus.

In this study, the majority of participants in CABG group were found to be in NYHA II, 7 (41.2\%) \& III, 7 (41.2\%). Majority of the participants' preoperative ejection fraction was more than $45 \%$ and $4(23.5 \%)$ participants had a family history of coronary artery disease. Lie et al conducted a study on predictors of outcome and the results were: mean age of participants was $62,90 \%$ of participants were male, history of previous MI (35\%), 46\% had a family history of the CAD, mean preoperative EF and NYHA class was 64.4 and 2.7, correspondingly.

In this study CABG group, the number of participants with high BMI was 9 (52.9\%) and normal weight, 7 (41.2\%). A study conducted in Brazil by Costa et al stratified participants based on BMI as healthy weight (32.0\%), overweight $(47.5 \%)$, and obese $(20.8 \%)$.

In this study, five $(29.4 \%)$ in CABG group and $4(17.4 \%)$ in valve group had a history of smoking and 9 (52.9 \%) in CABG group, $2(8.7 \%)$ in valve group were alcoholics. A total of 37 participants were non-vegetarians. Amongst 17 patients with coronary artery disease, one had left atrial myxoma and one had valvular heart disease. Triple vessel disease was observed in $88.2 \%$ of subjects. On pump CABG was performed commonly, 15 (88.2\%) and offpump CABG in $2(11.8 \%)$.

The findings of this study in contrast to the results of a study conducted by Adekola et al which showed triple-vessel disease in $39.26 \%$ and double-vessel disease in $32.59 \% .97 .78 \%$ of patients underwent on pump CABG. Off-pump CABG surgery was performed in $2.22 \%$ patients that is similar to the present study.

In the present study, a total of $14(60.8 \%)$ were found to be in NYHA III among patients underwent valve surgery. Among 23 participants in valve group, 11 (47.8\%) had preoperative atrial fibrillation. $47.8 \%$ of the participants in valve group had a history of previous cardiac operation. A study done by Alsoufi et al presented with 94 percent of participants in NYHA class III and IV, and $60 \%$ had a history of previous cardiac operations.

In this study, rheumatic heart disease was the common cause of valve disease $(73.9 \%)$ and others were degenerative valve disease (13\%), infective endocarditis (8.7\%), and $4.3 \%$ valvular heart disease (Aortic Regurtation due to ventricular septal defect). The commonly affected valve was the mitral valve, predominantly mitral stenosis, due to rheumatic etiology. The commonest cause of isolated aortic stenosis was degenerative calcific valve disease. Most of the participants had involvement of more than one valve.

This is similar to the findings of other study carried out by Manjunath et al demonstrated, in RHD, the pattern of involvement of valves was mitral $(60.2 \%)$, followed by aortic, tricuspid and pulmonary valves. Mitral stenosis was almost absolutely of RHD (97.4\%). Degenerative calcification was the common cause of isolated Aortic stenosis $(65.0 \%)$ followed by the bicuspid aortic valve $(33.9 \%)$ and rheumatic heart disease (1.1\%). More than one valve was affected in $(36.8 \%)$.

This finding was similar to the study carried out by Alsoufi et al showed that most common aortic and mitral valve disease was the rheumatic disease $(61 \%)$, followed by prosthetic valve dysfunction $(22 \%)$.

The present study showed an increased frequency of surgery on the single valve, $13(56.52 \%)$ was noted, followed by the double valve, $9(39.13 \%)$ and triple valve, $1(4.3 \%)$. A total of $12(52.2 \%)$ participants underwent MVR, 6 (26\%) of participants had AVR and $5(21.7 \%)$ participants had double valve replacement (DVR).

This is similar to results of the study conducted by Mangnall et al which showed the majority of participants were female $(63.5 \%)$, most of the participants underwent mitral valve replacement $(52 \%)$ followed by multiple valve 
replacement (29\%) and aortic valve replacement. The cause of the majority of valve replacement surgery (52\%) was mitral valve disease.

\section{Psychological outcome}

\section{Preoperative anxiety and Postoperative anxiety}

Most of the participants had normal range of anxiety (22-44 as per Zung anxiety scale) preoperatively and postoperatively in the current study. Gonçalves et al assessed the anxiety level in the preoperative period of heart surgery showed that 59.4\% (63) participants had minimal anxiety and $19.8 \%$ (21) had severe anxiety. A study conducted by Boni et al shows significant improvement in postoperative anxiety level.

\section{Quality of life}

The study showed that compared to preoperative quality of life, majority of subjects during postoperative period had good level of quality of life (QoL) in all dimensions including physical functioning, role limitations due to physical health, role limitations due to emotional problems, energy/fatigue, emotional well-being, social functioning, pain and perception of general health with statistical significance except social functioning.

It is similar to findings of a study conducted by Namazi et al showed that significant improvement in the quality of life score at 2 months after valve replacement $(p<0.001)$. Boni et al evaluated the quality of Life in patients undergoing coronary artery bypass grafting which showed significant improvement in the postoperative quality of Life.

The present study finding is also similar to the result of the study carried out by Rumsfeld et al showed improvement in physical and mental health status after surgery and identified preoperative health status as the key factor of change in the level of quality of life following operation.

\section{Limitation}

1. The sample size was small.

2. Group was not homogeneous.

3. Intraoperative variables were not included.

\section{Conclusion:-}

This study indicates better psychological outcome in patients who are undergoing CABG and valve surgery in JIPMER, Puducherry. The outcome of this study are similar to many studies conducted in various centre across the world.

\section{Implications}

The findings of the study can be applied in various areas of nursing namely nursing practice, nursing education, nursing administration and nursing research.

\section{Nursing practice}

The current study shows the aspects of psychological outcome in patients undergoing open heart surgery which includes pre and postoperative anxiety level and quality of life. This study stresses the importance of assessment of these aspects by nurses preoperatively and postoperatively. And it results in the better outcome of patients and prevention of complications. These aspects can be strengthened while planning for preoperative counseling and intervention.

\section{Nursing education}

It is important for the nursing students to know about the recovery process of patients undergoing cardiac surgeries in order to assess the risk factors, anxiety level, and provide preoperative education as well as discharge counseling. The curriculum of nursing students may include the detailed assessment of various factors and management of patients undergoing open heart surgery.

\section{Nursing administration}

The nurse administrators can apply these study findings to plan and implement various activities to improve outcome after cardiac surgeries. Preoperative and postoperative counseling services can be organized for the patients 
with the help of these findings. The healthcare professional should be motivated to provide these services through continuing education.

\section{Nursing research}

Evaluation of outcome of open heart surgery has quite a lot of aspects. The present study findings can be a basis for future research in this area. The study can be replicated with the larger population. Nurses can conduct studies to find various methods to improve the outcome of patients after cardiac surgeries.

\section{Recommendations for further research}

1. Studies can be conducted to assess the long-term outcome after cardiac surgeries.

2. The same study may be conducted with larger sample size and more components.

3. Similar studies can be done for the patients undergoing other cardiac surgeries.

4. Similar studies can be carried out to identify measures to improve outcome after cardiac surgery

\section{References:-}

1. What is coronary heart disease - NIH Health CAD (Internet). (USA). June 2016.Retrieved from https://www.nhlbi.nih.gov/health/health-topics/topics/cad

2. World health organization-NCD Country Profiles (Internet). (Place unknown).2011; (cited 2016 Mar 10).

3. Prabhakaran, D., Jeemon, P., Roy, A. (2016) Cardiovascular Diseases in India: Current Epidemiology and Future Directions, Circulation, 133, 1605-1620.

4. Maor,Y., Cohen, Y., Olmer, L., Mozes, B. (1999) Factors associated with health indicators in patients undergoing coronary artery bypass surgery, Chest, 116, 1570-1574.

5. Baberg, H.T., Dirlich, M., Laczkovics, A., Grewe, P., Bojara, W., De Zeeuw, J... Mugge, A. (2004) Determinants of health-related quality of life after aortic valve replacement in six-month survivors of intervention, J Heart Valve Dis, 13, 914-920.

6. Lee, D.H., Buth, K.J., Martin, B.J. (2010) Frail patients are at increased risk for mortality and prolonged institutional care after cardiac surgery, Circulation, 121, 973-978.

7. Sawatzky, A.V., Kehler, D.S., Ready, A.E. (2014) Rehabilitation program for elective coronary artery bypass graft surgery patients: a pilot randomized controlled study, Clin Rehabil, 28, 648-657.

8. Roques, F., Nashef, S.A.M., Michel, P., Gauducheau, E., de Vincentiis, C., Baudet, E., (1999) Risk factors and outcome in European cardiac surgery: analysis of the EuroSCORE multinational database of 19030 patients. European Journal of Cardio-thoracic Surgery, 15, 816-823.

9. Polit DF, Beck CT. (2007). Nursing Research: Principles and methods. Lippincott Williams \&Wilkins, 128.

10. Betty Neuman System theory. (Internet). (place unknown). 2012.Retrieved from http://currentnursing.com/nursing theory/Betty Neuman theory.html

11. Chaudhury, S., Sharma, S., Pawar, A.A., Kumar, B.K., Srivastava, M.K., Sudarsanan, S... Singh, D. (2006) Psychological Correlates of Outcome after Coronary Artery Bypass Graft, Ed J Armed Forces India, 62, 220223.

12. Filsoufi, F., Rahmanian, P.B., Castillo, J.G., Chikwe, J., Silvay, G., Adams, D.H. (2007) Results and predictors of early and late outcomes of coronary artery bypass graft surgery in octogenarians, JCardiothoracVascAnesth, $21,784-792$.

13. Lopez, V., Sek Ying, C., Poon, C.Y., Wai, Y. (2007) Physical, psychological and social recovery patterns after coronary artery bypass graft surgery: a prospective repeated measures questionnaire survey, Int J Nurs Stud, 44, 1304-1315.

14. Gallagher, R., McKinley, S., Dracup, K. (2004) Post discharge problems in women recovering from coronary artery bypass graft surgery, AustCrit Care, 17, 160-165.

15. Lie, I., Arnesen, H., Sandvik, L., Hamilton, G., Bunch, E.H. (2010) Predictors for physical and mental health 6 months after coronary artery bypass grafting: a cohort study, Eur J Cardiovasc Nurs, 9, 238-243.

16. Sadeghi, M., Hashemi, M., Sararoudi, R.B., Merasi, M.R., Molaeinezhad, M., Shamsolketabi, H. (2017) Demographic and psychological predictors of recovery from coronary artery bypass graft, J Edu Health Promot, 6, 92 .

17. Alsoufi, B., Rao, V., Borger, M.A., Maganti, M., Armstrong, S., Feindel, C.M... David T.E. (2006) Short- and long-term results of triple valve surgery in the modern era, AnnThorac Surg, 81, 2172-2177.

18. Oterhals, K., Hanssen, T.A., Haaverstad, R., Nordrehaug, J.E., Eide, G.E., Norekval, T.M., (2015) Factors associated with poor self-reported health status after aortic valve replacement with or without concomitant bypass surgery, EurJCardiothorac Surg, 48, 283-292. 
19. Sharma, D., Sisodia, A., Devgarha, S., Mathur, R.M. (2016) Evaluation of early postoperative complications after open heart surgery in Hepatitis-B positive patients, Heart India, 4, 56-60.

20. Sigurdsson, M.I., Helgadóttir, S., Ingvarsdottir, I.L., Viktorsson, S.A., Hreinsson, K., Arnórsson, T., Gudbjartsson, T. (2012) The outcomes of coronary artery bypass and aortic valve replacement in elderly patients, Laeknabladid, 98, 11-16.

21. Pieri M, Belletti A, Monaco F, Pisano A, Musu M, Dalessandro, V., Landoni, G. (2016) Outcome of cardiac surgery in patients with low preoperative ejection fraction, BMC Anesthesiol, 16, 97.

22. Adekola, O.O., Ogunleye, E.O., Kurien, J.G., Olusegun-Joseph, A., Ajayi, O.O., Ojo, O.O., Cherian, S. (2016) Experience with cardiac surgery in a private tertiary hospital in Chennai, India, Egypt J Cardiothorac Anesth, 10, 6-11.

23. Douki, Z.E., Vaezzadeh, N., Zakizad, M., Shahmohammadi, S., Sadeghi, R., Mohammadpour, R.A. (2010) Changes in Functional Status and Functional Capacity Following Coronary Artery Bypass Surgery, Pakistan Journal of Biological Sciences, 13, 330-334.

24. Namazi, P., Hossen, S.S., Mohammadi, N. (2015) Health-Related Quality of Life after Valve Replacement Surgery, Client-Centered Nursing Care, 1, 91- 94.

25. Costa, V.E., Ferolla, S.M., Reis, T.O., Rabello, R.R., Rocha, E.A., Couto, C.M... Bento, A. (2015) Impact of body mass index on outcome in patients undergoing coronary artery bypass grafting and/or valve replacement surgery, Rev Bras Cir Cardiovasc, 30, 335-342

26. Manjunath, C.N., Srinivas, P., Ravindranath, K.S., Dhanalakshmia, C. (2014) Incidence and patterns of valvular heart disease in a tertiary care high-volume cardiac center: A single center experience, Indian Heart J, 66, 320326.

27. Flegler, S., Paro, F.M. (2015) Factors Associated with Intubation Time and ICU Stay After CABG, Brazilian Journal of Cardiovascular Surgery, 30, 631-635.

28. Sattari, M., Baghdadchi, M.E., Kheyri, M., Khakzadi, H., Mashayekhi, S.O. (2013) Study of Patient Pain Management after Heart Surgery, Adv Pharm Bull, 3, 373-377.

29. Osinaike, B.B., Okikiolu, B., Olusesin, O. (2015) Prolonged intensive care unit stay after coronary artery bypass graft surgery: Role of perioperative factors, Niger Postgrad Med J, 22, 213-216.

30. Azarfarin, R., Ashouri, N., Totonchi, Z., Bakhshandeh, H., Yaghoubi, A. (2014) Factors Influencing Prolonged ICU Stay After Open Heart Surgery, Research in Cardiovascular Medicine, 3, e20159.

31. Torabipour, A., Arab, M., Zeraati, H., Rashidian, A., Sari, A.A., Sarzaiem, M.R. (2016) Multivariate Analysis of Factors Influencing Length of Hospital Stay after Coronary Artery Bypass Surgery in Tehran, Iran, Acta Med Iran, 54, 124-133.

32. Pato, M.F., Cláudio, G., Tammy, J.M., Adriano, C., Priscila, R.C., Luiz, G.P... Nunes M.C.P. (2015) Determinants of prolonged length of hospital stay after cardiac surgery: impact of rheumatic heart disease, MedicalExpress, 2, 1-8.

33. Totonchi, Z., Seifi, S., Chitsazan, M., Ghavidel, A.A., Baazm, F., Faritus, S.Z. (2014) Pain Location and Intensity During the First Week Following Coronary Artery Bypass Graft Surgery, Anesth Pain Med, 4, e10386.

34. De Mello, L.C., Rosatti, S.F.C., Hortense, P. (2014) Assessment of pain during rest and during activities in the postoperative period of cardiac surgery, Revista Latino-Americana de Enfermagem, 22, 136-143.

35. Guzman, M., Perez, C.M. (1998) Early postoperative complication after CABG at the cardiovascular center of pureto Rico and the Caribbean, PRHSJ, 17, 353-357.

36. Balasi, L.R., Paryad, E., Booraki, S.H, Leili, E.K., Meibodi, A. M. S., Sheikhani, N. N. (2015) Medication Adherence After CABG and Its Related to Medication Belief, Biomed Pharmacol J, 8,

37. Salari, S., Hasandokht, T., Roshan, M.M., Kheirkhah, J., Gholipour, M., Tootkaoni, P.M. (2016) Risk factor control, adherence to medication and follow up visit, five years after coronary artery bypass graft surgery, $\mathrm{J}$ Cardiovasc Thorac Res, 8, 152-157.

38. Sharaf, A.Y., Abd, E.A., Ibrahim, F., Elhamami, M. (2017) Knowledge and Adherence to Oral Anticoagulant Therapy among Patients with Mechanical Heart Valve Prosthesis, OSR Journal of Nursing and Health Science, 6, 9-29.

39. Ali, M.A., Yasir, J., Sherwani, R.N., Fareed, M., Arshad, R., Ismail, S... Fatima, K. (2017) Frequency and predictors of non-adherence to lifestyle modifications and medications after coronary artery bypass grafting: A cross-sectional study, 69, 469-473.

40. Gonçalves, K.K.N., Silva, J., Gomes, E.T., Pinheiro, L.L.S., Figueiredo, T.R., Bezerra, S.M.M. (2016) Anxiety in the preoperative period of heart surgery, Rev. Bras. Enferm, 69, 374-380. 
41. Boni, D., Martinez, J.E., Saccomann, I.C.R. (2013) Quality of Life of patients undergoing coronary artery bypass grafting, cta paul. Enferm, 26, 575-580.

42. Rumsfeld, J.S., Magid, D.J., O'Brien, M., McCarthy Jr, M., MaWhinney, S., Shroyer, A.L.W... Hammermeister, K.E. (2001) Changes in health-related quality of life following coronary artery bypass graft surgery, Annals of Thoracic Surgery, 72, 2026-2032.

43. Nicolini, F., Fortuna, D., Contini, G.A., Pacini, D., Gabbieri, D., Zussa, C... Gherli, T. (2017) The Impact of Age on Clinical Outcomes of Coronary Artery Bypass Grafting: Long-Term Results of a Real-World Registry, BioMed Res Int, 1-11.

44. Borrego, J.C., Doblas, J.J.G., Serrano, F.M.V., Bueno, F.C., Bailón, I.R., Sánchez-Espín, G.S. (2009) Influence of Sex on Perioperative Outcomes in Patients Undergoing Valve Replacement for Severe Aortic Stenosis, 62, 31-38.

45. Dos Santos, C. A., de Oliveira, M. A. B., Brandi, A. C., Botelho, P. H. H., Brandi, J. de C. M., dos Santos, M. A ... Braile, D. M. (2014) Risk factors for mortality of patients undergoing coronary artery bypass graft surgery, Cardiovascular, 29, 513-520. 